\title{
Unanticipated Quadraplegia in an Unconscious Mechanically Ventilated Traumatic Head Injured Patient
}

\author{
HA Ezike \\ TC Onyeka \\ VO Ajuzieogu \\ Department of Anaesthesia, \\ University of Nigeria \\ Teaching Hospital, Enugu \\ All Correspondence : \\ Dr HA Ezike \\ Departmnt of Anaesthesia \\ University of Nigeria Teaching \\ Hospital Enugu State.
}

\begin{abstract}
Objective

A significant number of unconscious patients who present to the emergency department as a result of Road Traffic Accident (RTA) or fall have a major injury to the Cervical Spine. This case highlights the problems of identification of such injuries in the unconscious.
\end{abstract}

\section{Case Report}

An unconscious young adult was admitted from the accident and emergency into the intensive care unit with a clinical impression of traumatic head injury. Neck collar was applied and the airway secured with an orotracheal tube. Following positive pressure ventilation for about ten minutes, the patient suddenly woke up to full consciousness and started shaking his head violently and uncontrollably, necessitating his tracheal extubation. He then complained of his inability to use or feel his limbs. Radiological investigation revealed complete dislocation of first $\left(\mathrm{C}_{1}\right)$ and second $\left(\mathrm{C}_{2}\right)$ cervical vertebra; a crack in the left temporal skull and a contused left lung. He was re-intubated about 20 minutes later when his respiratory efforts began to weaken, and ventilated under propofol sedation. He gradually became ventilator dependent, with collapse of cardiovascular and respiratory systems and died on thirteenth day of admission.

\section{Conclusion}

Cervical Spine injury should be suspected in all unconscious patients following trauma.

Key Words: Cervical Spine Injury, Quadriplegia, Mechanical Ventilation.

\section{Introduction}

$N$ evere neurological injuries are rarely seen in practice with upper cervical spine injuries because they are not usually compatible with life. ${ }^{1}$ True dislocation of the spinal column usually occurs in the cervical region, since the oblique and vertical directions of the articular processes do not permit dislocation without fracture in the dorsal and lumber regions. Forwards displacement of the atlas usually follows rupture of transverse ligament or fracture of the odontoid process. Dislocation between the atlas and the axis is usually seen in hanging or may occur as a result of lifting a child with hands encircling the neck from behind. Similar injury can result from a horizontal fall, with the head against an edge or shoulder, or hitting the head against unseen obstacle during a fast forward movement as was the case in our patient. Radiological evaluation of the upper cervical spine following such severe trauma is usually difficult but fractures occur in this part of the vertebra much more than ordinary cross-table lateral view can show. ${ }^{2}$ Survival after atlanto-axial-occipital ligamentous injury is uncommon and experience with immediate clinical management is similarly low.

\section{Case Presentation}

A 25-year old male undergraduate was admitted to the Accident and Emergency unit of the University of Nigeria Teaching Hospital, Enugu following an accidental bumping of the head against the staircase 
and a free fall down the stairs. Neurological review showed an unconscious patient with a Glasgow coma scale of $3 / 15$ and, with a small laceration at the occiput. He was not pale, anicteric and afebrile but in moderate respiratory distress. There was no rhinorrhoea, otorrhoea or bleeding from any orifice. Blood pressure was $110 / 60 \mathrm{mmHg}$, pulse of 68 beats per minute (bmp), respiratory rate of 22 per minute and a temperature of $36.2^{\circ} \mathrm{C}$. Central nervous system, examination in the emergency room showed normoreflexia of the limbs and very reactive pupils. The chest and abdomen were essentially normal. An impression of head injury secondary to a fall from height was made, to rule out subdural haemorhage.

Following an anaesthetic review, cervical injury was added to the list of differentials in accordance with our routine practice of such inclusion until proven otherwise, and patient admitted into the Intensive Care Unit after placing a neck collar. Oxygen saturation on room air was $90-92 \%$. As respiration gradually became irregular and saturation fluctuating over a wide range $86-92 \%$, a decision was made to place an orotracheal tube and mechanically ventilate the patient, to enable controlled uninterrupted movement for necessary investigations. With mechanical ventilation at a fractional inspired oxygen concentration of 50\% $\left(\mathrm{fiO}_{2}, 0.5\right)$ arterial oxygen saturation rose to $99 \%$, blood pressure appreciated to $130 / 83 \mathrm{mmHG}$, and a pulse to $84 \mathrm{bpm}$.

At about 10 minutes of mechanical ventilation when the patient was about to be taken to Radiology for skull X-Ray and C-T Scan, he suddenly regained consciousness and went into violent shaking of the head perhaps in efforts to communicate his protest against the endotracheal tube. he was obliged with extubation following which he spoke, complaining of his inability to feel or move his limbs. a neurological assessment this time revealed sensation levels up to C5 C6 on the right arm and T7, T8 on the anterior abdomen. No sensation at all on the lower limbs and the left arm. There was no power in both upper and lower limbs, no joint position sense but, there was hyperreflexia in all the limbs and spastic rigidity of the lower limbs. The impression was then modified to include traumatic quadriplegia. As respiratory distress gradually increased he was reintubated and ventilated under propofol sedation and then taken for Radiological investigations.

C-spine X-ray showed reversal of the usual cervical lordosis, with severe anterior subluxation at $\mathrm{C} 1$ and $\mathrm{C} 2$ the entire body of the atlas vertebra being anterior to the odontoid peg of the axis (figure 1). Skull x-ray showed crack in the left temporal bone and occipital
Soft tissue swelling.

Chest x-ray revealed contused left lung, with compensatory hyperinflation of the right lung. Other investigation results such as Full blood count, Electrolyte and Urea and Urinalysis were within normal limits.

He was commenced on normal saline infusion, 8 hourly intravenous dose of $8 \mathrm{mg}$ dexamethasone, $500 \mathrm{mg}$ ampicilin/cloxacilin 6 hourly and 8 hourly intravenous dose of $400 \mathrm{mg}$ metronidazole. Nasogastric tube was placed for feeding, the urethra catherized and strict input/output maintained. The scalp wound was dressed daily. A diagnosis of quadriplegia following traumatic atlanto-axial subluxation was made, probably with complete severance of the spinal cord at that level.

Skull traction was applied and trecheostomy carried out to assist respiratory management while he was being prepared for surgery. The patient was ventilated using synchronized intermittent mandatory ventilation at a tidal volume of $700 \mathrm{mls}$ and $\mathrm{FIo}_{2} 0.5$, with a protocol to gradually drop mandatory breaths. Attempts at weaning the patient off the ventilator resulted in gradual drop in patient's ventilator effort and, in level of consciousness. Full mechanical ventilation following each weaning attempt, resulted in commensurate recovery of consciousness. This pattern of ventilation and consciousness coupling however decreased gradually until consciousness was totally lost by the $13^{\text {th }}$ day. He had cardiac arrest some 8hours later that same day and could not be resuscitated.

\section{Discussion}

Approximately 5-10\% of unconscious patients who present to the emergency department as the result of road traffic accident or fall have a major injury to the cervical spine. ${ }^{4}$ Cervcial spinal injury occurs in $2 \%$ of victims of blunt trauma; the incidence is increased if the Glasgow Coma Scale score is less than 8 or if there is a focal neurologic deficit. ${ }^{6}$ Immobilization of the spine after trauma is of paramount importance in the management of these patients. The need to evaluate all at-risk patients with a complete and technically adequate imaging series seems to be accepted as the standard of care ${ }^{6}$ Most cervical spine fractures occur predominantly at 2 levels. One third of injuries occur at the level of $\mathrm{C} 2$, and one half subaxially ${ }^{4,6}$ mostly at the level of C6 or C7 and most devastating. ${ }^{5}$ But most fatal cervical spine injuries occur in upper cervical levels, either at craniocervical junction $\mathrm{C} 1$ or $\mathrm{C} 2$ as was the case in this patient.

Unconscious trauma patients must therefore, be assumed to have cervical spine injury until proven 
otherwise. Their necks must be immobilized as soon as help arrives at the scene of accident until evaluations show no injury. Soft collars are unsatisfactory as they permit $75 \%$ of neck movements while hard collars reduce flexion and extension to $30 \%$ and normal rotation and lateral movement to $50 \%$.

Safe management dictates prompt attention to the airway, breathing and haemodynamic stability, followed by central nervous system evaluation. Clinical evaluation of the cervical spine in a patient with blunt trauma could be unreliable. Blacksin and Lee $^{2}$ discovered that $8 \%$ of cervical fractures remain undetected following evaluations. Lateral, anteroposterior, and odontoid plain x-ray views of the cervical spine supplemented by computerized tomographic imaging can pick-up most of the injuries. To improve the suspicion index Goodrich et $\mathrm{al}^{5}$ have related age to cause of these cervical spine injuries. Between the ages of 15 and 24 years cervical spine injuries are usually as a result of high energy trauma, while above 55 years low energy trauma such as falling while in standing position.

Cervical spine injuries pose significant airway management challenge ${ }^{8,9}$. Clinical care interventions may on their own cause neurologic problems, a recognized fact but to prove otherwise in a medicolegally aware society requires more than ordinary reviews, to exclude injuries that could have resulted in neurological deficits. Airway maneuvers such as chin lift, jawthrust and direct laryngoscopy generally result in some degree of neck movement, more so at the point of injury. avoidance of direct laryngoscopy in suspected or known cases of cervical spine injuries has been advocated for fear of secondary neurologic injury. ${ }^{7}$ Our patient was a suspected head injured young man, deeply unconscious, with only a matter of routine to suspect cervical spine injury, who was intubated and ventilated with oxygen enriched air. $\mathrm{He}$ was discovered to be quadriplegic after he regained consciousness. Haqstings and Kelley ${ }^{8}$ reported similar experience in an unrecognized cervical spine injured patient who was discovered to be quadriplegic after bag-mask ventilation, direct laryngoscopy and cricothyroidotomy. In-line immobilization during such maneuvers limits these movements which are now said to be unlikely to result in any neurologic injury ${ }^{6-7}$ provided that reasonable care is taken during the exercise. Turkstra et $\mathrm{al}^{10}$ have demonstrated much reduced cervical spine motion during laryngoscopy with AirTraq laryngoscope compared with such motion following the use of Macintosh laryngoscope. Such reduced cervical spine motion during laryngoscopy will translate to greater safety in the management of cervical spine injured patients. However, deterioration is an inevitable consequence of providing care to spinal cord-injured patients and will surely occur in some patients despite acceptable care practices. $^{6}$

There is yet no appropriate technique for performing tracheal intubation in patients with cervical spine injury. The use of oesophageal obturator airway, or blind nasotracheal intubation have been advocated for the fact that either can be accomplished without hyperextension of the neck. ${ }^{11}$ Awake intubation, direct laryngoscopy and tracheal intubation following rapid sequence induction and the use of fibre-optic bronchoscope, all have practiced according to the dictates of equipment availability and experience without significant difference in their outcome. ${ }^{12}$

Cervical Spine injuries are not without other associated injuries. Only in $20 \%$ of instances are traumatic injuries restricted to the cervical spine. While $2-10 \%$ of patients with cranio-cerebral trauma have Cervical Spine injury, as much as $25-50 \%$ of patients with cervical spine injury, have an associated head injury. ${ }^{13}$ Our patient also had head injury and associated lung contusion. Such additional pulmonary complications usually result in hypoxia and hypercarbia, with greater need for urgent airway intervention, Morbidity and mortality are usually increased in patients with associated injuries. Claxton and colleagues ${ }^{14}$ in a retrospective study of 72 cases identified predictors of hospital mortality and mechanical ventilation in cervical spinal cord injury. Age, level of neurological lesion and Glasgow Coma Scale (GCS) level on arrival are independent predictors of early hospital death after traumatic cervical spinal cord injury. Similarly, Wicks and Menter ${ }^{15}$ in a ten year review of ventilator-dependent patients who could be weaned from mechanical ventilation and their long term survival, identified level of neurologic injury, age and associated injuries as determinants of weanability and mortality. Though age was on the side of our patient, the GCS of 3 on arrival, the unrecognized neurological lesion and the urgent airway control measures all put him well on the side of mortality.

In conclusion, cervical spine injury should be suspected in all unconscious patients following trauma. Airway control procedures must be designed to avoid inflicting secondary injuries. Survival depends on level of neurological injury, age of patients Glasgow Coma Scale on presentation and associated injuries. There may not be any consensus on the best airway control technique for the management of cervical spine injured patients in the 
near future but, the use of AirTraq laryngoscope, blind nasal intubation oesophageal obturator airway, awake intubation and in-line immobilization have practiced with degrees of success.

\section{References}

1. Kerr, and MacDonal, J.W. The Spine, Vertebral Column and Spinal Cord. In: Russell RCG, Williams NS, Bulstrode CJK (Eds) Bailey and Love's Short practice of Surgery, 24 ${ }^{\text {th }}$ edition 2004, Hodder education Publishers, London NWI 3BH 552-579.

2. Blacksin MF, and Lee HJ. Frequency and significance of fractures of the upper cervical spine detected by CT in patients with severe neck trauma. American journal of Roentgenology, 1995, 165 (5) 1201-1204

3. Crosby ET. Airway management after upper cervical spine injury. What have we learned? Can J Anesth. 2002;49: 733-744

4. Davenport M, Torma B Mueller TB, Blavai E, Roy SP. Fracture, cervical spine. E- medicine emergency medicine. http://emedicine. medicscape. com/article/ 824380 overview.

5. Allan Goodrich J, Thad Riddle, Samuel Hu. Lower cervical spine fractures andislocations. http//emedicine.medscape.com/article/1264065 .Overview July 2008

6. Crosby, Edward T. Airway Management in Adult after Cervical Spine Trauma. Anesthesiology 2006, 104: (6), 1293-1318.
7. Hastings RH, Marks JD. Airway Management for Trauma Patients with potential cervical Spine Injuries. Anesth. ANALG. 1991;73:471-82.

8. Hastings RH, Kelley SD, Neurologic Deterioration Associated with Airway Management in a Cervical Spine-Injured Patient. Anesthesiology 1993, 78: (3) 580-583.

9. Sims CA and Berger Dl. Airway Risk in Hospitalized Trauma Patients with Cervical injuries Requiring Halo Fixation. Ann. Surg. 2002, 235(2): 280-284.

10. Turkstra TP, Pelz DM, Jones PM. Cervical Spine Motion: A fluoroscopic comparison of the Air Traq laryngoscope verse the macintosh Laryngoscope Anesthesiolgy 2009; 111, (1):97101.

11. TrevoTr AD, Yson-H Udson, and Adam B. Stein. Acute Management of Traumatic Cervical Spinal Cord Injuries. The Mount Sinai Jour. Med. 1999, 66 (3). 170-178

12. Suderman VS, Crosby ET, Lui A. Elective Oral Tracheal Intubation in Cervical Spine Injured Adult- Occational review... Can. J. Anaesth. 1991,39 (6): from the Electronic Anesethsiology Library 1991-2005.

13. Sekhon LHS, Fehlings MG: Epidemiology, demographics and pathophysiology of acute spinal cord injury. Spine 2001; 26:S2-12.

14. Claxton AR, Wong DT, Chung F and Fehlings MG. Predictors of Hospital mortality and Mechanical Ventilation In patients with cervical spinal Cord Injury. Can J Anaesth. 1998; 45: $144-49$.

15. Wicks AB and Menter RR. Long-term outlook in quadriplegic patients with initial ventilator dependency. Chest 1996, 90 (3): 406-410. 